\title{
Correlation of Age, Gender, and Employment Status with Quality of Life Glaucoma Patient
}

\author{
Andi Hardianti ${ }^{1 \star}$, Nur Nasry Noor ${ }^{1}$, Lalu Muhammad Saleh ${ }^{2}$, Andi Nur Utami ${ }^{1}$, Iva Hardi Yanti ${ }^{1}$, Muliati Muliati ${ }^{3}$, Anwar Mallongi ${ }^{4}$ \\ ${ }^{1}$ Department of Epidemiology, Faculty of Public Health, Hasanuddin University, Makassar, Indonesia; ${ }^{2}$ Department of \\ Occupational Health and Safety, Faculty of Public Health, Hasanuddin University, Makassar, Indonesia; ${ }^{3}$ Department of Health \\ Promotion and Behavioral Sciences, Faculty of Public Health, Hasanuddin University, Makassar, Indonesia; ${ }^{4}$ Department of \\ Environmental Health, Faculty of Public Health, Hasanuddin University, Makassar, Indonesia
}

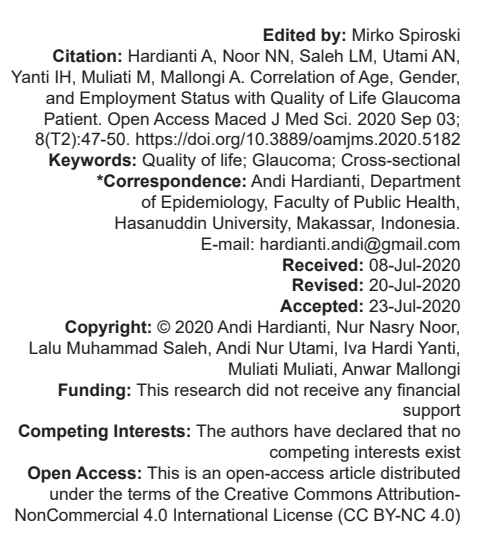

\section{Abstract}

BACKGROUND: People with glaucoma sometimes do not feel the symptoms of glaucoma until the end of the stage so the risk of blindness will be even greater. Glaucoma is a form of visual impairment, also the second cause of blindness after cataracts. However, in contrast to cataracts, glaucoma cannot be cured through surgery so that the blindness experienced is permanent.

AIM: This study aimed to determine the relationship between the characteristics of respondents (age, gender, and occupational status) and the quality of life of glaucoma patients.

METHODS: This study used quantitative research with cross-sectional method. Interviews were conducted on 250 glaucoma patients at community eye health centers. To determine age, sex, and employment status related to quality of life, the data were analyzed using Chi-square and logistic regression.

RESULTS: The age with p-value 0668 and gender with p-value employment status in 0237 and 0105 with $p$ values were not related to the quality of life of glaucoma patients. The results of logistic regression analysis showed that the employment status with a significance of 0046 was a factor related to the quality of life.

CONCLUSION: No relation to gender, age, and income with the quality of life of patients with glaucoma in Makassar Community Eye Health Centers in 2018 was found.

\section{Introduction}

Some glaucoma patients do not feel the symptoms of glaucoma until the end of the stage so that the risk of blindness will be even greater. Glaucoma is one form of visual impairment, also the second leading cause of blindness after cataract. However, unlike cataracts, glaucoma cannot be cured through surgery, thus suffered permanent blindness.

Glaucoma is a disease that damages the optic nerve so that the disruption of some or all of the visual field caused by high eye pressure someone, usually due to the barrier discharge eye (aqueous humor) [1]. The mechanism of the increase in intraocular pressure in glaucoma is a disorder aqueous humor outflow due to abnormalities of the anterior drainage system of the camera angle (open-angle glaucoma) or aqueous humor access to the drainage system.

The wider community of glaucoma do not know it, so it tends to ignore the symptoms. Glaucoma often develops without any symptoms or risk factors which are evident. Yet with intensive and regular treatment can reduce the pressure on the eyeball, thus slowing the occurrence of blindness.
Results of global data on visual impairment 2010 state the cause of visual impairment around the world that most refractive errors were not corrected, followed by cataract and glaucoma. Amounted to $18.0 \%$ cannot be determined, and $1 \%$ is vision disorders since childhood [2]. Glaucoma is a leading cause of blindness that cannot be cured globally. There are about 60.5 million people infected with primary openangle glaucoma and primary angle-closure glaucoma (primary-closed angle glaucoma) of 2010 [3].

According to epidemiological studies, the prevalence of glaucoma is highest in Germany by $14 \%$, and the second is Northern Europe (Russia) as much as $11.9 \%$. The lowest prevalence is that France is $3.4 \%$. Studies conducted in Spain showed that the prevalence of primary open-angle glaucoma is more prevalent in males is $2.4 \%$ compared to women is $1.7 \%$. These results are consistent with studies conducted in Germany that suggests that the incidence of glaucoma is higher in men (6.64\%) than in women $(2.96 \%)$. The number of blind people in Western Europe are 956000101300 (10.6\%) who had glaucoma [4]. 
Quality of life was rated as the individual's perception of their position in life according to the culture and values in life. Quality of life is influenced by physical health, psychological health, level of independence, social relationships, trust, and relationship with the environment [5]. Some have suggested that there are various factors that affect the quality of life of patients with glaucoma. These factors, among others are: education, knowledge, age, gender, occupation, length of illness, medical history, the severity, the sharpness of the eyes, wide field of view, a history of the disease, family history, and intraocular pressure.

\section{Materials and Methods}

This research was conducted at the Community Eye Health Center Makassar South Sulawesi. This type of research is observational using cross-sectional design.

The population of this research is all glaucoma Center in December 2017, January, and February 2018, which is in the process of treatment. The samples 224 selected by simple random sampling during the study managed to get a sample of 250 patients with glaucoma. The research sample of respondents who agreed to be interviewed by the signed informed consent has been issued by the Ethics Committee of the Faculty of Public Health, University of Hasanuddin.

Data collected through interviews to obtain data on age, sex, and employment status. Data quality of life obtained using a questionnaire from the National Eye Institute Visual Function - Questionnaire. Demographic data glaucoma patients in getting through direct interviews using a questionnaire.

Data analysis was performed using the Statistical Package for the Social Science version 20. The chi-square test was used to test the relationship between independent and dependent variables. Statistical significance was accepted at the 95\% confidence level. Logistic regression analysis was performed to identify factors associated with quality of life. Analysis of the variables with $p<0.25$ included in the logistic regression model analysis using the enter key to identify factors that can significantly affect the quality of life of patients with glaucoma.

\section{Results}

Glaucoma patients with good quality of life are $89.6 \%$ (224) and with a poor quality of life patients who visit Makassar Community Eye Health

is $10.4 \%(26)$ (Table 1 ). The results of the bivariate analysis showed that more male with glaucoma with a high quality of life are 128 respondents (92.3\%) while the female sex with a good quality of life are $87.7 \%$ (128). Patients with $\leq 57$ years of age with glaucoma and a high quality of life is $90.6 \%$ (96) of respondents, while in the age group $>57$ years, were $88.9 \%$ (128) of respondents with good quality of life. Marital status of the table can be seen that respondents with glaucoma with married status and quality of life are good, thereby 196 respondents $(92.9 \%)$, while the status of widows/ widowers, there are $78.3 \%$ (18) of respondents who have a quality of life for good and for status $62.5 \%$ which are unmarried (10) of respondents with a high quality of life. Education respondents with a good quality of life most frequent are the respondents with primary education that is 72 respondents (92.3\%). According to the characteristics of the respondents (employment status) respondents with a good quality of life are more frequent [148 (91.9\%)]. However, respondents who work and have a good quality of life $(100 \%)$, i.e., respondents with private employment/ state (14), TNI/Polri (2), and the Labor / PRT/Farmer (9) people (Table 2).

Table 1: Quality of life in glaucoma patients Community Eye Health Centers Makassar

\begin{tabular}{lll}
\hline Quality of life & Frequency $(\mathrm{n}=250)$ & $\%$ \\
\hline Well & 224 & 89.6 \\
Bad & 26 & 10.4 \\
\hline
\end{tabular}

The results of the analysis of the characteristics of respondents relationship glaucoma patients with glaucoma patient quality of life (Table 3 ), there is no significant relationship between gender and quality of life of patients with glaucoma with $p=0.237>a$ (0.05). Similar results were seen in the age group with $p=0.668>\alpha(0.05)$ which means that it is not related

Table 2: Distribution of respondents by characteristics in Community Eye Health Centers

\begin{tabular}{|c|c|c|c|c|c|c|}
\hline \multirow[t]{3}{*}{ Characteristics } & \multicolumn{4}{|c|}{ Quality of life $(n=250)$} & \multirow{2}{*}{\multicolumn{2}{|c|}{ Total }} \\
\hline & \multicolumn{2}{|c|}{ Bad } & \multicolumn{2}{|l|}{ Well } & & \\
\hline & $\mathrm{n}$ & $\%$ & $\mathrm{n}$ & $\%$ & $\mathrm{n}$ & $\%$ \\
\hline \multicolumn{7}{|l|}{ Gender } \\
\hline Woman & 18 & 12.3 & 128 & 87.7 & 146 & 100 \\
\hline Male & 8 & 7.7 & 96 & 92.3 & 104 & 100 \\
\hline Amount & 26 & 10.4 & 224 & 89.6 & 250 & 100 \\
\hline \multicolumn{7}{|l|}{ Age } \\
\hline$>57$ years & 16 & 11.1 & 128 & 88.9 & 144 & 100 \\
\hline$\leq 57$ years & 10 & 9.4 & 96 & 90.6 & 106 & 100 \\
\hline Amount & 26 & 10.4 & 224 & 89.6 & 250 & 100 \\
\hline \multicolumn{7}{|l|}{ Marital status } \\
\hline Single & 6 & 37.5 & 10 & 62.5 & 16 & 100 \\
\hline Married & 15 & 7.1 & 196 & 92.9 & 211 & 100 \\
\hline Widow widower & 5 & 21.7 & 18 & 78.3 & 23 & 100 \\
\hline Amount & 26 & 10.4 & 224 & 89.6 & 250 & 100 \\
\hline \multicolumn{7}{|l|}{ Education } \\
\hline Not school & 1 & 33.3 & 2 & 66.7 & 3 & 100 \\
\hline Elementary & 6 & 7.7 & 72 & 92.3 & 78 & 100 \\
\hline Junior high school & 0 & 0 & 19 & 100 & 19 & 100 \\
\hline High school & 13 & 12.2 & 88 & 87.1 & 101 & 100 \\
\hline College & 6 & 12.2 & 43 & 87.8 & 49 & 100 \\
\hline Amount & 26 & 10.4 & 224 & 89.6 & 250 & 100 \\
\hline \multicolumn{7}{|l|}{ Job status } \\
\hline Yes & 13 & 14.6 & 76 & 85.4 & 89 & 100 \\
\hline Civil servant & 9 & 26.5 & 25 & 73.5 & 34 & 100 \\
\hline Private/state & 0 & 0 & 14 & 100 & 14 & 100 \\
\hline Military/police & 0 & 0 & 2 & 100 & 2 & 100 \\
\hline Entrepreneur & 4 & 13.3 & 26 & 86.7 & 30 & 100 \\
\hline Labor/PRT/farmers & 0 & 0 & 9 & 100 & 9 & 100 \\
\hline No & 13 & 8.1 & 148 & 91.9 & 161 & 100 \\
\hline Amount & 26 & 10.4 & 224 & 89.6 & 250 & 100 \\
\hline
\end{tabular}


to age with quality of life of patients with glaucoma. Employment status variables are with $p=0.105>a$ $(0.05)$ so it can be stated that there is no correlation between age, gender, and employment status with the quality of life of patients with glaucoma in BKMM Makassar.

Table 3: Respondent characteristics variable distribution relationship with glaucoma patient quality of life in Community Eye Health Center Makassar

\begin{tabular}{|c|c|c|c|c|c|c|c|}
\hline \multirow[t]{3}{*}{ Characteristics } & \multicolumn{4}{|c|}{ Quality of life $(n=250)$} & \multirow{2}{*}{\multicolumn{2}{|c|}{ Total }} & \multirow[t]{3}{*}{$\mathrm{p}$-value } \\
\hline & \multicolumn{2}{|c|}{ Bad } & \multicolumn{2}{|c|}{ Well } & & & \\
\hline & $\mathrm{n}$ & $\%$ & $\mathrm{n}$ & $\%$ & $\mathrm{n}$ & $\%$ & \\
\hline \multicolumn{8}{|l|}{ Gender } \\
\hline Woman & 18 & 12.3 & 128 & 87.7 & 146 & 100 & \multirow[t]{3}{*}{0.237} \\
\hline Male & 8 & 7.7 & 96 & 92.3 & 104 & 100 & \\
\hline Amount & 26 & 10.4 & 224 & 89.6 & 250 & 100 & \\
\hline \multicolumn{8}{|l|}{ Age group } \\
\hline$>57$ years & 16 & 11.1 & 128 & 88.9 & 144 & 100 & \multirow[t]{3}{*}{0.668} \\
\hline$\leq 57$ years & 10 & 9.4 & 96 & 90.6 & 106 & 100 & \\
\hline Amount & 26 & 10.4 & 224 & 89.6 & 250 & 100 & \\
\hline \multicolumn{8}{|l|}{ Job status } \\
\hline Yes & 13 & 14.6 & 76 & 85.4 & 89 & 100 & \multirow[t]{3}{*}{0.105} \\
\hline No & 13 & 8.1 & 148 & 91.9 & 161 & 100 & \\
\hline Amount & 26 & 10.4 & 224 & 89.6 & 250 & 100 & \\
\hline
\end{tabular}

Table 4 shows factors most related to the quality of life of patients with glaucoma with $p=0.046$ is variable and meaningful employment status as a protective factor for the poor quality of life, with the value of Wald on quality of life that is 3.972 , which means that 3.972 times long illness related to the quality of life of patients with glaucoma.

\section{Discussion}

This study of 250 respondents found that more respondents have a good quality of life. The results of the Chi-square analysis of this study showed that there was no relationship between gender and quality of life. The results also showed that among the patients with glaucoma more men have a good quality of life [92.3\% (96)] compared to women [87.7\% (128)].

The findings are in line with Charafeddine et al. [6] that the sexes are not related to the quality of life with $p=0.114$. With cross-sectional study stated that male smokers have a better quality of life than women. In contrast to these results, the results of research [7] suggest that there is a relationship between gender and quality of life $(p=0.001)$. Although the results of these studies stated that there is a relationship between gender and quality of life, this study says that men have a better quality of life than women. The same result was shown by Hamzah et al. [8] that there is a relationship between gender and quality of life with $p=0.001$.

Table 4: Multivariate analysis of glaucoma patient quality of life in Community Eye Health Center Makassar

\begin{tabular}{clllllll}
\hline \multirow{2}{*}{ Research variable } & B & Wald & Sig. & $\operatorname{Exp~(B)~}$ & \multicolumn{2}{c}{ Cl 95\% } \\
\cline { 5 - 7 } & & & & & LL & UL \\
\hline Step 1 JK (1) & 0.381 & 2.486 & 0.115 & 2.066 & 0.893 & 5.091 \\
& Age (1) & 0.351 & 0.653 & 0.419 & 0.704 & 0.300 & 1.650 \\
& Working (1) & 0.865 & 3.972 & 0.046 & 0.421 & 0.180 & 0.986 \\
Constant & 2.456 & 0.84 & 0.000 & 11.654 & & \\
\hline
\end{tabular}

He also explained that women have estrogen when menopause will be reduced, thus increasing the risk of anxiety and depression that will drop mental health and quality of life.

The study also revealed that the differences that occur can occur due to the coping strategies of men and women differently. Men tend to focus on problems that occur while women focus more on emotion when faced with a problem that women are more likely to have negative emotions that in the long-term can lead to stress and decreased quality of life.

The results also showed that patients with glaucoma with good quality of life more in the age group $>57$ years are $90.5 \%$ (209) and which have a poor quality of life more in the age group $\leq 57$ years. It can be associated with more than half of the respondents that are already aged $>57$ years. In line with these results, Yuliati and Ririanty [9] got the result $p=0.266$ so that it can be seen that there is no relationship between age and quality of life. This study describes the elderly above 50 years, which is usually accompanied by a family, so there are people who accompanied. Old age is also mentioned that it is ready and accepts the illness that tends patient.

In contrast to the results of this study, the research by cross-sectional method revealed that there was a relationship between age and increasing the quality of life for the person's age that will decrease the quality of life. Glaucoma is a disease that is associated with age. Getting older, it will increase the risk of developing glaucoma. The risk of getting glaucoma will increase at age $40-64$ years at $1 \%$ and the age of 65 years at $5 \%$.

Analysis of employment status variable shows the results of $p=0105$, which means that there is no relationship between employment status and quality of life. The results of the Moons et al. [10] in contrast to these results say that there is a difference in the quality of life between the population's status as a student, the working population, people who are not working (or looking for work), and residents who are unable to work ( or have a certain disability). Research by Wahl et al. [11] found that employment status related to the quality of life for both men and women.

Results of Cheung et al. [12] found that employment status has a relationship with quality of life $(p=0.047)$ of patients sclerosing cholangitis. These results are consistent with research [13] that work affects the quality of life $p=0.041$ patients undergoing hemodialysis.

Status of respondents works closely with income obtained respondents. It relates to the daily fulfillment of the respondents also associated with the treatment performed. Ongoing treatment was followed by the cost of transportation used and the time taken to perform the treatment. In addition, the treatment effect of treatment carried out will have an impact on 
the productivity of the patient. Such activities can work both fixed and activities performed daily [14], [15], [16].

\section{Recommendation}

The need for socialization importance of eye examinations for high-risk groups as parents not end in blindness. The dissemination not only on high-risk groups to the family to know the early symptoms of glaucoma.

\section{Conclusion}

No relation to gender, age, and income with the quality of life of patients with glaucoma in Makassar Community Eye Health Centers in 2018.

\section{References}

1. Kemenkes RI. Infodatin, Data and Information Center for the Ministry of Health of the Republic of Indonesia. New Delhi: Ministry of Health; 2015.

2. World Health Organization. Global Data on Visual Impairments, 2010. Geneva: World Health Organization; 2012.

3. Tham YC, Li X, Wong TY, Quigley HA, Aung T, Cheng CY. Global prevalence of glaucoma and projections of glaucoma burden through 2040: A systematic review and metaanalysis. Ophthalmology. 2014;121(11):2081-90. https://doi. org/10.1016/j.ophtha.2014.05.013 PMid:24974815

4. Prokofyeva E, Zrenner E. Epidemiology of major eye diseases leading to blindness in Europe: A literature review. Ophthalmic Res. 2012;47:171-88. https://doi.org/10.1159/000329603 PMid:22123077

5. Quaranta L, Riva I, Gerardi C, Oddone F, Floriano I, Konstas AG. Quality of life in glaucoma: A review of the literature. Adv Ther. 2016;33:959-81. https://doi.org/10.1007/s12325-016-0333-6 PMid:27138604

6. Charafeddine $\mathrm{R}$, Demarest $\mathrm{S}$, Cleemput I, Van Oyen $\mathrm{H}$, Devleesschauwer B. Gender differences in the association between smoking and health-related quality of life in Belgium. Prev Med. 2017;105:280-6. https://doi.org/10.1016/j. ypmed.2017.09.016

PMid:28964851

7. Choi ES, Chang YK, Lee DH, Ko JH, Lim I, Bang $\mathrm{H}$, et al Gender-specific associations between quality of life and leukocyte telomeres length. Maturitas. 2018;107:68-70. https:// doi.org/10.1016/j.maturitas.2017.10.008 PMid:29169583

8. Hamzah R, Widaryati W. Age and Gender Relationship Quality of Life in Patients with Heart Failure in PKU Muhammadiyah Hospital in Yogyakarta. Indonesia: University Aisyiyah Yogyakarta; 2017.

9. Yuliati A, Ririanty M. Differences in quality of life elderly who live in the community with at elderly social services (the different of quality of life among the elderly who living at community and social services). Lib Health. 2014;2:87-94.

10. Moons P, Van Deyk K, Marquet K, Raes E, De Bleser L, Budts W, et al. Individual quality of life in adults with congenital heart disease: A paradigm shift. Eur Heart J. 2004;26(3):298307. https://doi.org/10.1093/eurheartj/ehi054 PMid: 15618044

11. Wahl AK, Rustøen T, Hanestad R, Lerdal A, Moum T. Quality of life in the general Norwegian population, measured by the quality of life scale (QOLS-N). Qual Life Res. 2004;13(5):1001-9. https:// doi.org/10.1023/b:qure.0000025583.28948.5b PMid:15233513

12. Cheung AC, Patel H, Meza-Cardona J, Cino M, Sockalingam S, Hirschfield GM. Factors that influence health-related quality of life in patients with primary sclerosing cholangitis. Dig Dis Sci. 2016;61(6):1692-9. https://doi.org/10.1007/s10620-015-4013-1 PMid:26743764

13. Sa'ed HZ, Daraghmeh DN, Mezyed DO, Khdeir RL, Sawafta MN, Ayaseh NA, et al. Factors affecting quality of life in Patients on hemodialysis: Across-sectional study from Palestine. BMC Nephrol. 2016;17(1):44. https://doi.org/10.1186/s12882-016-0257-z PMid:27117687

14. Stang S, Mallongi A, Dwinata I, Sumarni S. Risk factor model for pulmonary tuberculosis occurrence in Makassar using spatial approach. Enferm Clin. 2020;30(4):383-7. PMid:32545093

15. SyamA, Palutturi S, Djafar N,Astuti NB, ThahaAR. Micronutrients, academic performance and concentration of study: A literature review. Int J Appl Bus Econ Res. 2016;14(5):2831-43. https:// doi.org/10.5455/ijmsph.2017.10062016596

16. Patimah S, Arundhana Al, Mursaha A, Syam A. Development of foxtail millet and flying fish flour-based cookies as functional food. Curr Res Nutr Food Sci. 2019;7(2):504-16. https://doi. org/10.12944/crnfsj.7.2.20 